\title{
Comparative Study of HBV, HCV and HDV Serological Markers among Acute Hepatitis B, Chronic Hepatitis B, Apparently Healthy Patients
}

\author{
Thaer Kadhim Fayyadh ${ }^{1}$, Fuying $\mathrm{Ma}^{1}$ \\ ${ }^{I}$ College of Life Science and Technology, Huazhong University of Science and Technology, Wuhan 430074, \\ China, E-mail address: tkadhum@yahoo.com \\ ${ }^{1}$ Key Laboratory of Molecular Biophysics of MOE, College of Life Science and Technology, Huazhong \\ University of Science and Technology, Wuhan 430074, China
}

\begin{abstract}
Objective: In the present study we investigated the HBV infection among different types of patients by analyzing the seroprevalence of specific viral serological markers for detecting antigens and antibodies and follow up the biochemical parameters as well as determined the risk factors for infection. Method: A total of 165 patients (70 with $C H B, 35$ with $A H B$ and 60 with $A H C$ ) from both genders. The patient's blood specimens were tested for the $A L T$, TSB levels and HBV serological markers then underwent for screening for coinfection with HCV or HDV using ELISA technique. Results: Among AHB patients, the serological markers showed a high prevalence of anti-HBc IgM, anti-HBc Total and HBeAg, with a low rate of coexistence HBeAg/anti-HBe and anti-HBe and there were no anti-HBs markers. In CHB patients, low rate of anti-HBc IgM, HBeAg, and anti-HBe but the high rate of anti-HBc Total was recorded, whereas coexistence of HBsAg/ anti-HBs and HBeAg/anti-HBe was present in a low rate. In AHC group, anti-HBc IgM and coexistence of anti-HBs/HBsAg were absent, high rate of anti-HBc Total and anti-HBe, low rate of HBeAg and coexistence of HBeAg lanti-HBe. Comparison between markers among the three types of $H B V$ infection showed significant importance $(P<0.05)$ with the exception of HBeAg marker, which was showed insignificant importance $(P>0.05)$. The biochemical tests of TSB and ALT showed a significant correlation $(P<0.05)$ among the three types of infection. The frequency parenteral drug administration, previous blood transfusion and more than one risk factor were showed significant importance $(P<0.05)$ in the transmission of HBV. Coinfection of both HDV and HCV among HBV patients with chronic infection existed with low significant rates. Conclusion: Differences in baseline HBV serological markers were detected in patients with various types of $H B V$ infection. Frequency parenteral drug administration and blood transfusion is the major risk factor for transmission of HBV infection. Coinfection of HDV and HCV infection is possible.
\end{abstract}

Keywords: $H B V$, serological Markers, $A H B$ patient, $C H B$ patient.

Abbreviate: hepatitis $B$ surface antigen (HBsAg), anti-HBs, anti-HBc IgM and $\operatorname{Ig} G$, hepatitis $B$ e antigen (HBeAg) and anti-HBe, Acute hepatitis B patient (AHB), Chronic hepatitis B patient (CHB), Apparently healthy carriers $(A H C)$.

\section{Introduction}

Hepatitis B virus (HBV) is a circular, partly double-stranded DNA virus, belongs to the Hepadnaviridae family. HBV infection is responsible for the most of the acute and chronic liver diseases worldwide leading to severe liver diseases such as cirrhosis and hepatocellular carcinoma (HCC) (Perz, et al., 2006; WHO, 2015). The infection is transmitted by sexual, parenteral and vertical route (Ott, et al., 2012). Serological markers for HBV infection consist of HBsAg, anti-HBs, anti-HBc IgM, anti-HBc IgG, HBeAg and anti-HBe (Kramvis, 2014). Along with active vaccination against $\mathrm{HBV}$ infection, one significant method to diminish the burden of this disease is the diagnosis of acute, chronic and occult HBV infection which can be achieved first by using HBV serological markers for detecting antigens and antibodies (Song and Kim, 2016). In the clinical setting, patients with HBV infection have different clinical presentations. On initial evaluation in the clinic, routine liver function tests, and HBV serological markers tests are obtained for diagnosis. Thereafter, patients may be placed into one of the several clinical categories (Tong, et al., 2008). More difficult to categorize the (HBsAg)-positive patients who are asymptomatic, have normal liver function tests, and whose liver biopsy results may not be available to assist with diagnosis (Pungpapong, et al., 2007). A report from the Agency for Healthcare Research and Quality on the management of HBV suggested that patients in different clinical stages of HBV needed to be more clearly defined since antiviral treatment guides for hepatitis B are based on specific categories of patients (Wilt, et al., 2008). In the present study, we were determining the frequency of these markers in different clinical types of HBV infection. The HBV markers among patients with AHB showed a high prevalence of anti-HBc 
IgM and anti-HBc Total markers. A high rate of $\mathrm{HBeAg}$ with a low rate of anti-HBe; in addition, an absence of anti-HBs and low rate of coexistence of $\mathrm{HBeAg}$ with anti-HBe was seen. In $\mathrm{CHB}$ patients, low rate of anti-HBc IgM, high rates of anti-HBc Total and coexistence of $\mathrm{HBeAg} /$ anti-HBe and $\mathrm{HBsAg} / \mathrm{anti}-\mathrm{HB}$ s was present in low rate among this group. In AHC group, anti-HBc IgM was absent; high rate of anti-HBc Total was noticed; low rate of $\mathrm{HBeAg}$, high rate of anti-HBe, high rate of coexistence of $\mathrm{HBeAg}$ with anti-HBe and absence of anti-HBs were recorded among this group. Comparison between HBV serological markers among the three types of infection showed significant importance $(\mathrm{P}<0.05)$, with the exception of $\mathrm{HBeAg}$ marker which was of insignificant importance. The biochemical tests of TSB and ALT showed a significant correlation $(\mathrm{P}<0.05)$ among the three types of $\mathrm{HBV}$ infection. Regard to the risk factors of transmission, a frequent parenteral drug administration, previous blood transfusion and more than one risk factor showed significant importance $(\mathrm{P} \leq$ 0.05). The coinfection of HDV or HCV among HBV patients existed with a low significant rate among patients with chronic infection.

\subsection{Patients and blood specimen's collection}

\section{Materials and Method}

The study group was randomly selected from patient's individuals in Baghdad. A total of 165 patients; 70 with CHB infection, 35 with AHB or clinically suspected of HBV infection and 60 AHC group. A total of $119(72.12 \%)$ patient males and $46(27.87 \%)$ females were admitted to hospitals in Baghdad with a male to female ratio 2.58-1. From each patient, $5 \mathrm{ml}$ of blood samples were collected to investigate the ALT, TSB levels and HBV serological markers including HBsAg (screening and confirmatory), anti-HBs, anti-HBc (IgM and $\mathrm{IgG}$ ), HBeAg, anti-HBe, anti-HCV screening and anti-HDV (IgM, IgG). This group submitted for a special questionnaire about their history, such as; received blood or blood product, underwent a surgery in their life, and when to be contacted with the carrier of Hepatitis.

\subsection{Biochemical and Serological Assays}

The alanine aminotransferase test (ALT), (normal range, up to $13 \mathrm{u} / \mathrm{l}$ ) and total serum bilirubin (TSB), (normal range, less than 1 $\mathrm{mg} / \mathrm{dl}$ ) levels (Young, 1997), were done for all patients at initial examination by using commercially available ELISA kits (Randox, UK). Serological markers for HBV were done for each specimen using commercially available ELISA kits (Bioelisa; Biokit, Spain). The assay for each serological marker was done according to the manufacturer's instruction.

\subsection{Statistical analysis}

Statistical analysis was performed with SPSS software version 15, under windows XP and Mini. Tab programmers'. Data were analyzed using analysis of paired samples T-test for comparison between different groups. Results were reported as mean \pm S.D and differences were considered as significant when $\mathrm{P}<0.05$.

\subsection{Study of HBV markers among AHB patients}

\section{Results and Discussion}

Table (1) shows the distribution of HBV serological markers among 35 patients with AHB infection

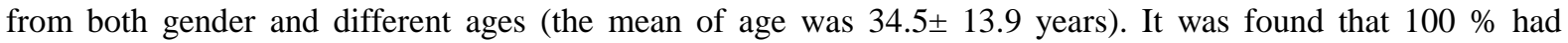
anti-HBc IgM, which was considered as a best serological marker of acute HBV infection. The high level of IgM-specific anti-HBc is frequently detected at the onset of clinical illness because such antibody is directed against the $27 \mathrm{~nm}$ internal core component of $\mathrm{HBV}$ and its appearance in serum is indicative of viral replication (Jawetz et al., 2007). As well as, all patients (100\%) have appeared with anti-HBc Total, which developed in all $\mathrm{HBV}$ infection and appeared shortly after HBsAg in acute disease, during acute infection, both anti-HBc IgM and Total markers emerges 1-2 weeks after the presence of HBsAg (CDC, 2008; Song and Kim, 2016). Whereas $\mathrm{HBeAg}$ marker was found in 18 cases with rate of $51.4 \%$, in the past, this result indicates that those patients were highly infectious, $\mathrm{HBeAg}$ and anti-HBe had been used to know infectivity and viral replication, but their use for this purpose has mostly been replaced by HBV DNA assay (Dény and Zoulim, 2010). However, active viral replication is sustained in some patients with HBeAg seroconversion due to mutations in the core / pre-core region that inhibit or decrease the production of $\mathrm{HBeAg}$ (Kao, 2008). Besides, an anti-HBe marker was present in low rate $(11.2 \%)$, this low seroconversion from $\mathrm{HBeAg}$ to anti-HBe indicating that only a few patients in this group progression toward a resolution of the disease, whatever, $\mathrm{HBeAg}$ to anti-HBe seroconversion is related to the remission of hepatic disease (Dény and Zoulim, 2010). Also, the results showed the absence of anti-HBs indicated no recovery, science the anti-HBs is known as a neutralizing antibody and confers long-term immunity (Weber, 2005).

The low coexistence of HBeAg / anti-HBe in this group; about $42.8 \%$ had negative results for both markers indicates that those patients may have low levels of wild-type HBV or presence of stop codon mutation in the core / pre-core region that prevents the production of HBeAg which lead to prevent production of 
anti-HBe antibodies (Schiff, 2004; CDC, 2008).

Table (1): Seroprevalence of HBV serological markers in AHB patients

\begin{tabular}{|c|c|c|c|c|c|c|}
\hline $\begin{array}{c}\text { Total } \\
\text { AHB } \\
\text { Patients }\end{array}$ & $\begin{array}{l}\text { anti-HBc IgM } \\
\text { positive }\end{array}$ & $\begin{array}{c}\text { anti-HBcT } \\
\text { positive }\end{array}$ & $\begin{array}{l}\text { HBeAg } \\
\text { positive }\end{array}$ & $\begin{array}{l}\text { anti-HBe } \\
\text { positive }\end{array}$ & $\begin{array}{l}\text { anti-HBs } \\
\text { positive }\end{array}$ & $\begin{array}{c}\text { HBeAg and } \\
\text { anti-HBe } \\
\text { Negative }\end{array}$ \\
\hline & No. \% & No. \% & No. & No. & No. & No. $\%$ \\
\hline 35 & $\begin{array}{ll}35 & 100\end{array}$ & $\begin{array}{ll}35 & 100\end{array}$ & 51.4 & 11.2 & 0 & 42.8 \\
\hline
\end{tabular}

\subsection{Study of HBV serological markers among CHB patients}

A total of $70 \mathrm{CHB}$ patients from both genders were tested. The mean age of patients was $39.5 \pm 14.6$ years. Table (2) illustrates a distribution of HBV markers among those patients group. The results were recorded; low rate of anti-HBc IgM (14.28 \%) and high rate of anti-HBc Total (97.1\%), since the anti-HBc IgM is generally detectable 4 to 6 months after onset of illness and it is considered as the best serological marker of acute $\mathrm{HBV}$ infection as well as anti-HBc IgM marker of activity of the disease, which is usually increased in acute phase and falls to a low titer or undetectable level after 6 months, but may become detectable again during reactivation of infection, whereas anti- $\mathrm{HBc}$ Total present in acute and chronic hepatitis B infection (Berenguer and Wright, 2002; Mortensen et al., 2016).

Table (2): Seroprevalence of HBV serological markers in CHB patients

\begin{tabular}{|c|c|c|c|c|c|c|}
\hline $\begin{array}{l}\text { Total CHB } \\
\text { Patients }\end{array}$ & $\begin{array}{c}\text { anti-HBc IgM } \\
\text { positive }\end{array}$ & $\begin{array}{c}\text { anti-HBcT } \\
\text { positive }\end{array}$ & $\begin{array}{l}\text { HBeAg } \\
\text { positive }\end{array}$ & $\begin{array}{c}\text { anti-HBe } \\
\text { positive }\end{array}$ & $\begin{array}{c}\text { anti-HBs } \\
\text { positive }\end{array}$ & $\begin{array}{c}\text { HBeAg and } \\
\text { anti-HBe } \\
\text { negative }\end{array}$ \\
\hline & No. $\%$ & No. $\%$ & No. \% & No. $\%$ & No. \% & No. $\%$ \\
\hline 70 & $10 \quad 14.28$ & $\begin{array}{ll}68 & 97.1\end{array}$ & $24 \quad 34.3$ & $29 \quad 41.4$ & 2.8 & 31.4 \\
\hline
\end{tabular}

While all 70 patients with HBsAg persistence for more than 6 months, with low a rate of anti-HBc IgM in their sera, indicated chronic HBsAg carriers (Mast, et al., 2005). In addition, the prevalence rate of $\mathrm{HBeAg}$ and anti-HBe markers was $34.3 \%$ and $41.4 \%$ respectively; these results agreed with previously reported in Iraq (Al-Jaaf, 2006). Regarding the negative results of coexistence HBeAg /anti-HBe, the high rate (31.4\%) among CHB patients may suggest that high numbers mutant strains of $\mathrm{HBV}$ exist among patients, indeed, there are high prevalence rate of HBeAg-negative mutants in Mediterranean countries compared to North European countries and USA (Tahan et al., 2003). Coexistence of HBsAg /anti-HBs were detected in $2.8 \%$ among this group, occasionally, many studies had been reported that the coexistence of HBsAg /anti-HBs in patients (Song and Kim, 2016). In most cases, anti-HBs antibodies are unable to neutralize the HBV, thus these patients are regarded as carriers of HBV (Mortensen et al., 2016). This result is consistent with an early report in Iraq (Al-Salmani, 1986).

\subsection{Study of HBV serological markers among AHC group}

Table (3) shows the distribution of HBV markers among 60 AHC patients with a mean of ages $32.72 \pm$ 7.074. In this group, the seroprevalence of anti-HBc IgM marker did not score at all patients, while the seroprevalence of the anti-HBc Total marker was found among all patients. This result indicates inactive HBV replication, since the anti-HBc IgM is a marker of activity of disease, however, serologic markers including HBsAg, anti-HBc levels begin to decrease, and even become undetectable in 6-12 months after acute infection, while these markers still exist in patients with chronic infection (Shepard, et al., 2006). Regarding the $\mathrm{HBeAg}$ and Anti-HBe markers, the present study found that the seroprevalence rate was $34.3 \%$ and $58.3 \%$, respectively. These results in line with previous studies were done in Iraq (Al-Jaaf, 2006). And maybe those individuals have acquired the infection perinatally, there is commonly a prolonged period with normal serum ALT levels, positive sera for $\mathrm{HBeAg}$, and minimal or no liver inflammation (McMahon, 2005). The high rate of anti-HBe (58.3\%) among this group indicated that those individuals undergo seroconversion to anti-HBe antibodies and enter in into the inactive carrier's stage or progress to HBeAg-negative chronic hepatitis (Tong, et al., 2010).The coexistence rate of $\mathrm{HBeAg} /$ anti-HBe was high among this group. These differences in seroprevalence of HBeAg among AHC patients could be explained due to core / pre-core variants (Tahan et al., 2003).

Table (3): Seroprevalence of HBV markers among AHC group

\begin{tabular}{|c|c|c|c|c|c|c|}
\hline $\begin{array}{l}\text { Total } \\
\text { AHC }\end{array}$ & $\begin{array}{c}\text { anti-HBc IgM } \\
\text { positive }\end{array}$ & $\begin{array}{l}\text { anti-HBcT } \\
\text { positive }\end{array}$ & $\begin{array}{l}\mathrm{HBeAg} \\
\text { positive }\end{array}$ & $\begin{array}{l}\text { anti-HBe } \\
\text { positive }\end{array}$ & $\begin{array}{c}\text { anti-HBs } \\
\text { positive }\end{array}$ & $\begin{array}{c}\mathrm{HBeAg} \text { and Anti-HBe } \\
\text { negative }\end{array}$ \\
\hline & No. $\%$ & No. $\%$ & No. $\%$ & No. $\%$ & No. $\%$ & No. $\%$ \\
\hline 60 & 0 & $\begin{array}{ll}60 & 100\end{array}$ & 34.3 & 58.3 & 0 & 15 \\
\hline
\end{tabular}




\subsection{Comparison between serological markers of $\mathrm{HBV}$ among different type of $\mathrm{HBV}$ infection}

The comparison between HBV serological markers among AHB, CHB and AHC groups was illustrated in table (4). It has been found a significant correlation $(\mathrm{P}<0.05)$ among the three groups regarding anti-HBcT, which was $100 \%$ among AHB and AHC groups and $97.1 \%$ in $\mathrm{CHB}$ group. This result consistent with the previously reported (CDC, 2008; Berenguer and Wright, 2002). The same finding was recorded in Iraq (Youssif, 1998). The anti-HBc IgM has been found with significant correlation ( $\mathrm{P}<0.05)$ among AHB, CHB and AHC group with rates of $100 \%, 21.4 \%$ and $0 \%$ among respectively. On the one hand, this finding agreed with a previously published report (Berenguer and Wright, 2002). On the other hand, the results of anti-HBc IgM among AHB patients group in the present study is higher than that was previously reported in Iraq (Marcus et al., 1993), This difference may due to early stage of acute infection among patients in present study, particularly with decreased existence of anti-HBe antibodies (11.2\%), or due to variability titer of anti-HBc IgM that increased in CHB phase but generally lower than that of acute phase (Coppola et al., 1996), while among AHC group there is compatible with previous studies were done in Iraq (Al-Mashhadani, 1998). Moreover, HBeAg positivity was $51.4 \%, 35.7 \%$ and $34.3 \%$ among $\mathrm{AHB}, \mathrm{CHB}$ and $\mathrm{AHC}$ group respectively with insignificant importance (P > 0.05), while anti-HBe showed an increase from $11.2 \%$ in AHB group to $60 \%$ in CHB group then decreased to $58.3 \%$ among AHC group with significant correlation $(\mathrm{P}<0.05)$.

Table (4): Comparison between HBV serological markers among different type of HBV infection

\begin{tabular}{ccccccc}
\hline $\begin{array}{c}\text { HBV Serological } \\
\text { Markers }\end{array}$ & \multicolumn{2}{c}{$\begin{array}{c}\text { AHB patients } \\
\text { group (35) }\end{array}$} & \multicolumn{2}{c}{ CHB patients } & \multicolumn{2}{c}{$\begin{array}{c}\text { AHC group } \\
\text { group (70) }\end{array}$} \\
\hline & No. $\%$ & No. & $\%$ & No. & $\%$ \\
Anti-HBcT positive & 35 & 100 & 68 & 97.1 & 60 & 100 \\
Anti-HBc IgM positive & 35 & 100 & 81 & 21.4 & 0 & 0 \\
HBeAg positive & 18 & 51.4 & 25 & 35.7 & 61 & 34.3 \\
Anti-HBe positive & 4 & 11.2 & 42 & 60.0 & 35 & 58.3 \\
Anti-HBs positive & 0 & 0 & 2 & 2.8 & 0 & 0 \\
HBeAg /anti-HBe negative & 15 & 42.8 & 22 & 31.4 & 15 & 25 \\
\hline
\end{tabular}

These results indicate an early stage of AHB infection and active replication or may be mutant strains of HBV exist that replicate without producing HBeAg (WHO, 2002). The present results of HBV serological markers in AHB and CHB groups similar to the previous studies were done in Iraq, while among AHC group in this study, the results of seroprevalence rates of $\mathrm{HBeAg}$ and anti-HBe was $34.3 \%$ and $58.3 \%$ respectively, these results incompatible with many previous studies done in Iraq (Al-Waysi, 2005; Al-Jaaf, 2006). These differences may be due to increase existence of $\mathrm{HBe}$-negative mutant $\mathrm{HBV}$ strains in Iraq. The high rates of anti-HBe indicating those individuals undergo seroconversion to anti-HBe positive and enter into the inactive carrier's stage or progress to HBeAg-negative chronic hepatitis (Tong, et al., 2010).

\subsection{Distribution of $\mathrm{HBV}$ infection among patients according to the risk factors}

Table (5) shows the suspected major risk factors for transmission of HBV infection. It was found that $20 \%$ due to frequent parenteral drug administration, with significant differences $(\mathrm{P}<0.05), 19.4 \%$ due to previous blood transfusion that is considered as

Table (5): Predisposing factors of hepatitis B among $165 \mathrm{HBV}$ patients

\begin{tabular}{lcc}
\hline \multicolumn{1}{c}{ Risk factors* } & Numbers & $\%$ \\
\hline Frequent parenteral drug administration & 33 & 20.0 \\
Previous blood transfusion & 32 & 19.4 \\
Positive family history & 5 & 3.03 \\
Previous surgery & 13 & 7.87 \\
Dental work & 3 & 1.8 \\
Chronic disease** & 7 & 4.24 \\
Unknown & 6 & 3.36 \\
More than one risk factor*** & 66 & 40.0 \\
Total & 165 & 100 \\
\hline
\end{tabular}

- Some patients might have more than one risk factor, ${ }^{*}$ *Chronic disease included (renal failure, thalassemia and hemophilia), *** About $40 \%$ of this group had dental work as a one of mixed factor.

an important mode of transmission of HBV infection, with significant correlation $(\mathrm{P}<0.05)$, as well as about half of patients $(40.0 \%)$ had more than one risk factor with significant correlation $(\mathrm{P}<0.05)$, while previous surgery history (due to poor equipment sterilization, not blood transfusion) formed $7.87 \%$, chronic disease formed $4.24 \%$ and positive family history was $3.03 \%$, whereas the lowest rate $(1.8 \%)$ was located in patients who previously had dental work and all these risk factor rates show statistically insignificant $(\mathrm{P}>0.05)$. Another 
group of patients with a rate of $3.36 \%$ unknown risk factors, this group had insignificant importance $(\mathrm{P}>0.05)$. The results of HBV infection transmitted through risk factors such as frequent parenteral drug administration, previous blood transfusion, chronic disease and more than one risk factor in present study agree with previous study around the world (Lemoine, et al., 2014), as well as with several previous studies done in Iraq (Youssif, 1998, Al-Waysi, 2005 and Al-Jaaf, 2006). But our results regarding the "previous surgery" is incompatible with previous studies were done in Iraq, that may be due to the improvement hygienic situation of the Iraqi hospitals such as destruction of disposable needles, and adequate sterilization of reusable surgical instruments (Schiff, 2004). Indeed, the unsafe blood and blood products transfusion and medical procedures, particularly in resource-poor settings, persist being important routes of transmission to individuals and in turn their susceptible contacts (Lemoine, et al., 2014). The low rate of "positive family history" may be related to the increased awareness and health education among Iraqi community. And the lowest rate of "dental work" as a risk factor did not indicate the improvement hygienic situations in clinic dentist because the highest rate (40\%) was located among dental work in patients who had more than one risk factor. However, the differences might be partly explained by varying risk factors and transmission routes across countries and between patients (Schweitzer, et al., 2015).

\subsection{Biochemical parameters among patients with different types of $\mathrm{HBV}$ infection}

Biochemical tests, including TSB, ALT levels, were done for all patients with HBV infection and AHC group (table 6). In AHB and CHB patient groups, the level of TSB was increased with a mean of $2.28 \pm 0.78$ and $2.06 \pm 0.65$ respectively with significant difference $(\mathrm{P}<0.05)$. While the least level located within AHC group with mean $0.85 \pm 0.10$. The result of TSB in present study consistent with that was previously reported in Iraq (Al-Waysi, 2005; Al-Jaaf, 2006). The results of ALT in all patients with AHB infection had elevated significantly in comparison with $\mathrm{CHB}$ patients and this finding compatible with many previous reports (Leblebicioglu et al., 2004; Pungpapong, et al., 2007), While the ALT results among AHC group was showed decreasing in comparison with both AHB and CHB patient groups, this finding agrees with early report in Iraq (Al-Salmani, 1986). Besides, these results may reflect that those individuals in the inactive chronic stage which characterized by anti-HBe positive, normal or slightly elevated ALT values (Tong, et al., 2010).

Table (6): Biochemical parameters among different types of HBV infection

\begin{tabular}{cccc}
\hline $\begin{array}{c}\text { Parameters/ normal } \\
\text { value }\end{array}$ & $\begin{array}{c}\text { AHB patient (35) } \\
\text { Mean } \pm \text { SD }\end{array}$ & $\begin{array}{c}\text { CHB patients (70) } \\
\text { Mean } \pm \text { SD }\end{array}$ & $\begin{array}{c}\text { AHC group (60) } \\
\text { Mean } \pm \text { SD }\end{array}$ \\
\hline $\begin{array}{c}\text { TBS } \\
\text { Less than 1mg/dl }\end{array}$ & $2.28 \pm 0.78$ & $2.06 \pm 0.65$ & $0.85 \pm 0.10$ \\
$\begin{array}{c}\text { ALT } \\
\text { Up to 13U / L }\end{array}$ & $40.4 \pm 5.87$ & $33.45 \pm 7.07$ & $19.26 \pm 1.51$ \\
\hline
\end{tabular}

\subsection{Seroprevalence of HDV and HCV markers among HBV patients}

Table (7) shows seroprevalence of serological markers of HDV and HCV among different types of HBV patients. A total of 165 individuals with AHB, CHB patients and AHC group were tested with anti-HDV total, anti-HDV IgM, and anti-HCV. It was found that $1.42 \%$ with anti-HDV total positive and $0 \%$ anti-HDV IgM among CHB patients, while no evidence of presence both HDV markers among AHB patients and AHC group. The overall prevalence of anti-HDV antibody was $0.6 \%$, and this result is incompatible with several earlier studies that were done in Iraq; (Al-Salmani, 1986; Rassam et al. 1988).

Table (7): prevalence of HDV and HCV markers among HBV patients

\begin{tabular}{|c|c|c|c|c|c|c|c|}
\hline \multirow[t]{2}{*}{$\begin{array}{c}\text { Type of } \\
\text { infection }\end{array}$} & \multirow[t]{2}{*}{ No. tested } & \multicolumn{2}{|c|}{$\begin{array}{c}\text { anti-HDV } \\
\text { IgM }\end{array}$} & \multicolumn{2}{|c|}{$\begin{array}{c}\text { anti-HDV } \\
\text { Total }\end{array}$} & \multicolumn{2}{|c|}{$\begin{array}{c}\text { anti-HCV } \\
\text { Abs }\end{array}$} \\
\hline & & No. & $\%$ & No. & $\%$ & No. & $\%$ \\
\hline AHB & 35 & 0 & 0 & 0 & 0 & 0 & 0 \\
\hline CHB & 70 & 0 & 0 & 1 & 1.48 & 1 & 1.48 \\
\hline AHC & 60 & 0 & 0 & 0 & 0 & 0 & 0 \\
\hline Total & 165 & 0 & 0 & 1 & 0.6 & 1 & 0.6 \\
\hline
\end{tabular}

While present study results were in line with recent studies results were done in Iraq (Al-Anbari, 2008), as well as with newly studies around the world (Leblebicioglu et al., 2004; Villa et al., 2015). These differences between the earlier and newly studies could be attributed to a decline in the prevalence of chronic $\mathrm{HBsAg}$ carriers in the general population (WHO, 2002). Also, table (7) showed the prevalence of anti-HCV Abs among CHB patients was $(1.42 \%)$ and overall prevalence was $0.6 \%$ among AHB, CHB patient and AHC group. The result is consistent with many studies around the world (Kucharska, et al., 2016). Whereas the rate of anti-HCV Abs in the present study was lower than previously published report in Iraq (Al-Mashhadani, 1998). The differences between previous study and this study may be associated with the regular screening of blood 
donations, increased awareness and health education or may reflect the small size of the study population was used, and this result indicated that coexistent of $\mathrm{HBV}$ and $\mathrm{HCV}$ infection possible.

\section{Conclusion}

Differences in baseline HBV serological markers were detected in patients with various types of HBV infection. Anti-HBc IgM was the best serological marker of AHB infection and present in CHB but absent in AHC group. Anti-HBc total presence in all types of infection while an absence of HBeAg and anti-HBe together in different types of HBV infection indicated a low level of wild-type HBV or present of stop codon mutation in the pre-cor region. Concurrent positivity of HBsAg and anti-HBs were detected in low rate among CHB patients. Frequency parenteral drug administration and blood transfusion is the major risk factor for transmission of HBV infection. Biochemical parameters (ALT \& TSB) were elevated more in AHB and CHB patients than AHC group. The prevalence of HDV among patients with different types of HBV infection was lower than previous figures. As well as co-existent of $\mathrm{HBV}$ and $\mathrm{HCV}$ infection is possible.

\section{References}

[1]. Al-Anbari K, (2008). Super infection and co-infection in HDV in patients with HBV infection. A thesis of High Diploma. College of Health and Medical technology. Foundation of Technical Education. Baghdad.

[2]. Al-Jaaf MA, (2006). A study of hepatitis B virus pre-core mutation among Iraqi chronic hepatitis B patients treated with interferon Alfa. M. Sc. thesis. Council of genetic engineering and Biotechnology. University of Baghdad.

[3]. Al-Mashhadani I, (1998). Sero-epidemiological study on HBV and HCV infections

[4]. among health care workers. Ph. D. thesis. College of Medicine. Baghdad University.

[5]. Al-Salmani AM, (1986). Clinical and laboratory assessment of hepatitis B surface antigen healthy carriers. M. Sc. thesis. College of Medicine, University of Baghdad.

[6]. Al-Waysi A, (2005). Effectiveness of interferon-alfa and lamivudine drugs in the treatment of chronic viral hepatitis (B \&C) among Iraqi patients. Ph.D. thesis. College of Medicine. Baghdad University.

[7]. Berenguer M, Wright TL, (2002). Viral hepatitis. In: Sleisenger and Fordtran's Gastrointestinal and liver disease. Pathphysiology $/$ diagnosis / management. Edited by Feldman M, Friedman LS and Sleisenger MH 2002.3: 1278

[8]. Centers for Disease Control and Prevention (2008). Epidemiology and Prevention of Vaccine-Preventable Diseases, Atkinson W, Hamborsky J, Mclntyre I, Wolfe S, eds. $10^{\text {th }}$ ed., Washington DC: Public Health Foundation. pp: 211-234.

[9]. Coppola R, Rizzetto M, Bradhy DW, (1996). Hepatitis B. In: Viral hepatitis Handbook. Edited by Crivelli-O-Saluggra (Vercelli)-Italy; p: 38-49.

[10]. Dény P, Zoulim F, (2010). Hepatitis B virus: from diagnosis to treatment. Pathol Biol; 58: 245-53.

[11]. Jawetz G, Melnick J, Adelberg S, (2007). Hepatitis viruses. In: Medical Microbiology. Brooks F, Butel S, Morse A, and Carroll C, eds. $24^{\text {th }}$ ed. McGraw-Hill; pp: 466-485.

[12]. Kao H, (2008). Diagnosis of hepatitis B virus infection through serological and virological markers. Expert Rev Gastroenterol Hepatol. 2:553-62

[13]. Kramvis A, (2014). Genotypes and genetic variability of hepatitis B virus. Inter virology. 57:141-50

[14]. Kucharska M, Inglot M, Szymczak A, (2016). Co-Infection of the Hepatitis C Virus With Other Blood-Borne and Hepato tropic Viruses Among Hemophilia Patients in Poland. Hepat Mon. 16:e35658.

[15]. Leblebicioglu H, Eroglu C, and members of the Hepatitis Study Group. (2004). Acute hepatitis B virus infection in Turkey: epidemiology and genotype distribution. Clin Microbial Infect. 10: 537-541

[16]. Lemoine M, Eholié S, Lacombe K, (2014). Reducing the neglected burden of viral hepatitis in Africa: strategies for a global approach. J Hepatol. 62: 469-76.

[17]. Marcus S, Al-Moslih M, Al-Tawil G, et al., (1993). Virological and Immunological studies in patients with acute viral hepatitis. Scand Immunology; 37: 256 .

[18]. Mast E, Weinbaum C, Fiore A, et al., (2005). A comprehensive immunization strategy to eliminate transmission of hepatitis B virus infection in the United States: recommendations of the Advisory Committee on Immunization Practices (ACIP) part 1: immunization of infants, children, and adolescents. MMWR Recomm Rep. 54:1-31

[19]. McMahon, J., (2005). Epidemiology and natural history of hepatitis B. Semin Liver Dis. 25:3-8

[20]. Mortensen E, Kamali A, Schirmer P, (2016). Are current screening protocols for chronic hepatitis B virus infection adequate? Diagnostic Microbiology and Infectious Disease. 85: 159-167

[21]. Ott J, Stevens A, Groeger J, et al., (2012). Global epidemiology of hepatitis B virus infection: new estimates of age specific HBsAg seroprevalence and endemicity. Vaccine; 30:2212-9.

[22]. Perz F, Armstrong L, Farrington A, et al., (2006). The contributions of hepatitis B virus and hepatitis C virus infections to cirrhosis and primary liver cancer worldwide. $J$ Hepatol; 45: 529-538.

[23]. Pungpapong S, Kim R, Poterucha J, (2007). Natural history of hepatitis B virus infection: an update for clinicians. Mayo Clin Proc. 82:967-975

[24]. Rassam W, Omer R, Niazi M, (1988). Delta virus infection in asymptomatic HBV carriers and patients with chronic liver disease in Iraq. Viral hepatitis and liver disease; 421 . Alan R. Liss. Inc

[25]. Schiff R, (2004). Hepatitis B. In: Hepatitis learning guide. Published by, Abbott diagnostics, a division of Abbott Laboratory Inc. USA. www.abbottdiagnostics.com

[26]. Schweitzer A, Horn J, Mikolajczyk R, et al., (2015). Estimations of worldwide prevalence of chronic hepatitis B virus infection: a systematic review of data published between 1965 and 2013. Lancet; 386: 1546-55.

[27]. Shepard W, Simard P, Finelli L, et al., (2006). Hepatitis B Virus Infection: Epidemiology and Vaccination. Epidemiol Rev. 28: 112-125

[28]. Song JE, Kim DY, (2016). Diagnosis of hepatitis B. Ann Transl Med; 4: 338. DOI: org/10.21037/atm.2016.09.11

[29]. Tahan V, Ozdogan O, Tozun N, (2003). Epidemiology of hepatitis in the Mediterranean Basin. Annales Academice Medicae Bialostocensis. 48: 11-17

[30]. Tong J, Hsien C, Hsu L, et al., (2008). Treatment recommendations for chronic hepatitis B: an evaluation of current guidelines based on a natural history study in the United States. J Hepatol. 48:1070-1078

[31]. Tong J, Hsu L, Hsien C, et al., (2010). A comparison of hepatitis B viral markers of patients in different clinical stages of chronic 
infection. Hepatol Int; 4:516-522

[32]. Villa D, Cortes-Mancera F, Payares E, (2015). Hepatitis D virus and hepatitis B virus infection in Amerindian communities of the Amazonas state, Colombia. Virology Journal. 12:172

[33]. Weber B, (2005). Recent developments in the diagnosis and monitoring of HBV infection and role of the genetic variability of the S gene. Expert Rev Mol Diagn. 5:75-91

[34]. Wilt J, Shamliyan T, Shaukat A, et al., (2008). Management of chronic hepatitis B. Evidence Report / Technology Assessment No. 174. AHRQ Publication No. 09-E002. Rockville, MD: Agency for Healthcare Research and Quality; October 2008. Prepared by the Minnesota Evidence based Practice Center under Contract No. 290-02-0009

[35]. World Health Organization (WHO). Hepatitis B. Fact sheet n²04. WHO, 2015. Available:http://www.who.int/mediacentre/factsheets/fs204/en/.Accessed11 Jan 2016.

[36]. World Health Organization (WHO). (2002) /CDS/ CSR / LYO /. 2: Hepatitis B. http:// www.who.int/emc

[37]. Young S, (1997). Effects of drugs on clinical laboratory tests. $3^{\text {rd }}$ ed. AACC Press. (According to Linear chemical comp.)

[38]. Youssif H, (1998). Immunological study of patients with chronic active hepatitis B. Ph.D. Thesis. College of Medicine. University of Baghdad. 